\title{
How many carboxyl groups does an average molecule of humic-like substances contain?
}

\author{
I. Salma and G. G. Láng \\ Eötvös University, Institute of Chemistry, Budapest, Hungary \\ Received: 17 April 2008 - Published in Atmos. Chem. Phys. Discuss.: 29 May 2008 \\ Revised: 18 August 2008 - Accepted: 5 September 2008 - Published: 17 October 2008
}

\begin{abstract}
The carboxyl groups of atmospheric humic-like substances (HULIS) are of special interest because they influence the solubility in water, affect the water activity and surface tension of droplets in the air, and allow formation of chelates with biologically active elements. Experimentally determined abundances of the carboxyl group within HULIS by functional group analysis are consistent with our knowledge on the average molecular mass of HULIS if the number of dissociable carboxyl groups is assumed to be rather small. The best agreement between the average molecular mass derived from the existing abundance data and the average molecular mass published earlier occurs for assuming approximately one dissociable carboxyl group only. This implies that HULIS can not be regarded as polycarboxilic acid in diluted solutions. The average molecular mass of HULIS derived from our electrochemical measurements with the assumption of one dissociable carboxyl group or equivalently, one dissociable sulphate ester per molecule ranges from 250 to $310 \mathrm{Da}$. It was concluded that HULIS are a moderately strong/weak acid with a dissociation constant of about $\mathrm{p} K=3.4$, which fits well into the interval represented by fulvic and humic acids. The mean number of dissociable hydrogen (i.e. of carboxyl groups and sulphate esters jointly) in HULIS molecules was refined to be between 1.1 and 1.4 in acidic solutions.
\end{abstract}

\section{Introduction and overview of the relevant experimen- tal data}

Aerosol particles containing large amounts of water-soluble organic compounds can play an important role in climate change, and they affect the environment and human health

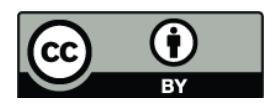

Correspondence to: I. Salma

(salma@chem.elte.hu) substantially (Fuzzi et al., 2006; Tsigaridis and Kanakidou, 2007). The uncertainties connected to their composition and interactions with the other aerosol components in droplets and with atmospheric gases hinder the quantification of their impacts (McFiggans et al., 2006). Valuable information on some specific compounds, classes of compounds or functional groups within the water-soluble organic fraction has become available in recent years. One of the most important groups is atmospheric HUmic-LIke Substances (HULIS) (Graber and Rudich, 2006). HULIS are present ubiquitously in the continental troposphere, and their carbon content makes up a mass fraction up to about $60 \%$ of the finesized water-soluble organic carbon (Salma et al., 2007, and references therein). They are regarded to be extremely heterogeneous partly polymeric system with strong poly-acidic, colloidal and chromophoric properties and substantial surface activity. They could not be resolved at the molecular level but they are known to be comprised of aromatic compounds with aliphatic chains (Graber and Rudich, 2006). Hence, HULIS are defined operationally which is connected to conceptual and experimental disadvantages. Moreover, there is no evidence that HULIS isolated from aerosol samples collected in different environments of the world or seasons are actually the same supramolecular system or class of compounds. Furthermore, spontaneous change in the aggregation and conformational states of HULIS molecules can take place under even slightly changing solution conditions, and, therefore, uniform properties for such a complex mixture cannot always be expected. These features largely complicate their research.

Composition, properties and interactions of HULIS are being studied by a large variety of experimental methods and techniques. Functional group analysis by ${ }^{1} \mathrm{H}-\mathrm{NMR}$ spectroscopy based on the approach proposed by Decesari et al. (2000) was successfully applied to identify and measure directly the abundance of several organic functional groups including carboxyl and hydroxyl groups (Tagliavini et al.,

Published by Copernicus Publications on behalf of the European Geosciences Union. 
Table 1. Estimated average molecular mass for atmospheric humiclike substances with different number of functional groups $(\mathrm{Ar}$ means aromatic core).

\begin{tabular}{lccccc}
\hline $\begin{array}{l}\text { Functional group, its mean } \\
\text { abundance and standard de- } \\
\text { viation within HULIS in } \\
\mathrm{m} / \mathrm{m} \%\end{array}$ & & & & \\
\hline & & 1 & 2 & 3 & 4 \\
\hline $\mathrm{COOH}$ & $5.4 \pm 0.4^{\mathrm{a}}$ & 834 & 1667 & 2501 & 3335 \\
$\mathrm{Ar}-\mathrm{OH}$ & $3.1 \pm 2.5^{\mathrm{a}}$ & 549 & 1097 & 1646 & 2194 \\
$\mathrm{COOH}$ & $25^{\mathrm{b}}$ & 177 & 353 & 530 & 706 \\
\hline
\end{tabular}

a Samburova et al. (2007); ${ }^{\mathrm{b}}$ Tagliavini et al. (2006) (see also the text).

2006; Decesari et al., 2006; Samburova et al., 2007). The carboxyl group content is of special interest because it influences the solubility in water, which is one of the major media in atmospheric, climatic or environmental processes. It also affects the water activity and surface tension of droplets in the air which are two crucial properties in cloud or fog droplet formation, hygroscopic growth and water activation. Furthermore, the carboxyl groups endow these molecules with the ability to form chelates with multivalent cations (e.g. precipitate trace elements with biological role in some media and make their solutions in other media), and thus to influence the bioavailability and biogeochemical cycling. A hypothetical model compound representing the chemical composition of polyacids (PA) chemical fraction (that is expected to consist mostly of HULIS) has been proposed, which has a molecular mass of $731 \mathrm{Da}$ and contains four carboxyl and two hydroxyl groups (Decesari et al., 2006).

A chemical derivatization version of the ${ }^{1} \mathrm{H}-\mathrm{NMR}$ spectroscopy was applied in a comprehensive way for several chemical fractions obtained from aerosol samples collected in the Amazon Basin (Tagliavini et al., 2006). The PA chemical fraction was obtained by ion-exchange chromatography from one $\mathrm{PM}_{2.5}$-fraction aerosol sample collected in the dry season. The percentage of the carboxyl carbon with respect to the total moles of carbon in the PA fraction (mol\%) was presented in the paper, and the mass percentage of the carboxyl group required for our purposes was derived using the whole experimental data set by the authors of the paper cited above, and the result is given in Table 1. A direct version of the ${ }^{1} \mathrm{H}-\mathrm{NMR}$ method was utilized recently to quantify the content of some functional groups including the carboxyl group and hydroxyl group bound to the aromatic moieties in pure HULIS isolated from $\mathrm{PM}_{1}$-fraction suburban-type aerosol samples (Samburova et al., 2007). The mean relative amount of carboxyl and hydroxyl groups together with their standard deviations calculated for the summer and winter HULIS samples are also included in Table 1.
The main objectives of this paper are to present a body of indirect evidence for the number of dissociable carboxyl functional group in an average HULIS molecule of approximately one, to discuss the consistency in our knowledge, to present and interpret experimental data on the average molecular mass and acid dissociation constant of HULIS in diluted solutions, and to formulate some conclusions for the dissociation of HULIS.

\section{Experimental}

Details on the samples, experimental procedures, conditions and data treatment as well as the measured results were presented in Salma et al. (2008). The experimental procedure used in that study is summarized briefly as follows: aerosol samples were collected by DHA- 80 high volume aerosol sampler equipped with a $\mathrm{PM}_{2.5}$ pre-separator (Digitel Elektronik, Switzerland) and operated for one week in central Budapest from in July 2006. Whatman QM-A quartz fiber filters were used as the collection substrate. The main section of the aerosol filters was utilized for isolation of pure HULIS by a modified one-step solid-phase extraction (SPE) method (Varga et al., 2001; Salma et al., 2008) on Oasis HLB columns (Waters, USA). A set of eight HULIS aqueous samples was prepared for electrochemical conductivity measurements. The first aqueous sample was made by adding $600 \mu 1$ water to an isolated pure HULIS sample with a mass of approximately $6 \mathrm{mg}$. It was put into ultrasonic bath for $15 \mathrm{~min}$, after which it was allowed to stand in an ultra-thermostat at a temperature of $20^{\circ} \mathrm{C}$ for one day. Finally, the $\mathrm{pH}$ and conductivity of the aqueous sample were measured. After the measurements, an aliquot of the HULIS aqueous sample was taken out, it was filtered through a syringe PVDF membrane filter with a pore size of $0.22 \mu \mathrm{m}$ and with a dead volume of $10 \mu \mathrm{l}$ (Millipore, USA), and the dissolved total organic carbon (TOC) concentration in the filtrate was measured by TOC analyzer. The remaining volume of the aqueous sample was diluted further with water, and the sample preparation and measurements were accomplished as described above. The consecutive dilution factors of the aqueous samples were 1.9, 2.1, 2.0, 2.6, 1.6, 1.9 and 10 .

The TOC concentrations for HULIS solutions were determined by a Multi N/C 2100S total organic carbon analyzer (Analytik Jena, Germany). The mass concentration of dissolved HULIS was calculated from the TOC data by using an organic matter-to-organic carbon mass conversion factor of 1.81 derived especially for the same type of HULIS (Salma et al., 2007). The concentration of HULIS varied from approximately $5 \mathrm{gl}^{-1}$ to $7 \mathrm{mgl}^{-1}$. The relative uncertainty of the measured results was estimated to be less than $2 \%$. Conductivity of the HULIS aqueous samples was derived by using electrochemical impedance spectroscopy. An electrochemical measuring cell with an effective volume of $500 \mu 1$ was made of glass and it was equipped with Pt working 
electrodes. All measurements were performed at a constant temperature of $20^{\circ} \mathrm{C}$ applying a sinusoidal perturbing signal with an amplitude of 5 or $10 \mathrm{mV}$ over a frequency range of $1 \mathrm{~Hz}$ to $13 \mathrm{kHz}$. The relative uncertainty of the conductivity was estimated to be less than $2 \%$. The $\mathrm{pH}$ of the aqueous sample was measured by a glass micro-electrode.

\section{Results and discussion}

\subsection{Abundance of carboxyl group}

The abundances of the carboxyl group within HULIS presented in Table 1 were utilized to calculate the average molecular mass of HULIS supposing that an average molecule contains from one to four carboxyl or hydroxyl groups. The corresponding molecular masses are summarized in Table 1 as well. It has to be noted here that the functional group abundance data derived from the ${ }^{1} \mathrm{H}-\mathrm{NMR}$ measurements are not always coherent and can involve large uncertainties as discussed in Fuzzi et al. (2001). Hence, the reliability of the mass values calculated by the abundances adopted from the literature should be also approached with caution in general, and they can be utilized for comparisons involving additional knowledge or background information. It is seen in Table 1 that the masses assuming one carboxyl group per molecule were 180 and $830 \mathrm{Da}$ obtained from the data of Tagliavini et al. (2006) and Samburova et al (2007), respectively. The difference between the numbers is rather significant. It can have different explanations besides the uncertainty issue indicated just above. The main causes include the fact that HULIS from different environments (in this case from an environment strongly affected by tropical biomass burning and from an urban environment) are not necessarily the same system of compounds due to the very different, mostly primary and secondary source processes, respectively. Furthermore, the isolation methods applied were discrepant which may also cause substantial differences in the results. In addition, it should be considered that the former value is only based on a single sample, and the unaccounted carbon in the fraction made up about $35 \mathrm{~mol} \%$. Moreover, our HULIS sample was isolated from urban-type aerosol which is expected to be much more similar to those dealt with by Samburova et al. (2007) than to biomass burning aerosol. Therefore, we rely primarily on the data reported by Samburova et al. (2007). The average molecular mass of HULIS isolated from rural fine-sized aerosol samples by the SPE method was determined by HPLC-MS, and by vapour pressure osmometry. The values obtained were between 200 and $300 \mathrm{Da}$, and between 215 and $345 \mathrm{Da}$, respectively (Kiss et al., 2003). Samburova et al. (2005) applied size exclusion chromatography-UV spectroscopy, and laser desorption/ionization mass spectrometry to determine the molecular mass distribution of $\mathrm{PM}_{10}$-fraction urban HULIS, and they derived an upper limit of approximately $700 \mathrm{Da}$. The av- erage molecular mass for HULIS isolated from fresh smoke particles, slightly aged wood burning smoke particles, and local photochemical pollution particles was estimated to be 610,410 , and $500 \mathrm{Da}$, respectively using a spectrophotometrical method based on empirical correlation relationships between the molar absorptivity and molecular mass (Dinar et al., 2006). The average molecular mass for urban-type HULIS obtained by the same correlation relationships as above varied from 373 to $763 \mathrm{Da}$ with an overall mean value of $556 \mathrm{Da}$ (Salma et al., 2008).

The estimates assuming two carboxyl groups in a molecule of the urban-type HULIS seem to be already outside or at the upper end of the molecular mass range set by the data reported earlier. The estimates corresponding to four or three carboxyl groups are of the order of several thousands and are substantially larger than any molecular mass data summarized above. It seems, therefore, unlikely that an average molecule of HULIS originating from urban environments contains three or more carboxyl groups in diluted solutions.

The conclusion on the rather limited number of carboxyl groups per molecule is also coherent with the findings achieved by $\mathrm{pH}$ titration and dissociation constant $(\mathrm{p} K)$ spectroscopy (Samburova et al., 2007). The authors observed a clear and large maximum in the distribution of HULIS dissociation constant around 4.0 and a smaller maximum around 5.5. The smaller $\mathrm{p} K$ value likely represents the carboxyl groups. There actually could be several carboxyl groups present in the molecules but the majority of them should have rather similar dissociation values.

\subsection{Average molecular mass}

The electrochemical conductivity $(\kappa)$ experimentally determined was utilized to calculate the average molecular mass $(M)$ of HULIS. The acid dissociation (acidity) constant $(K)$ assuming one dissociable carboxyl group in a HULIS molecule can be expressed by the apparent dissociation degree $\alpha=\Lambda / \Lambda_{0}$, with $\Lambda=\kappa / c$ being the molar conductivity and $\Lambda_{0}$ being the molar conductivity at infinite dilution (limiting molar conductivity) as:

$$
K=\frac{\alpha^{2} c}{1-\alpha},
$$

where $c$ is the initial molar concentration of HULIS in the solution. Equation (1) can be rearranged to a linear equation that relates the measured quantities:

$$
\frac{m / V}{\kappa}=\frac{M}{K \Lambda_{0}^{2}} \kappa+\frac{M}{\Lambda_{0}},
$$

where $m / V$ is the mass concentration of HULIS in the solution. The relationship between $m / V / \kappa$ and $\kappa$ is displayed in Fig. 1. It is seen that for the most diluted solutions (for the five samples with the smallest concentrations) the dependence is linear with a correlation coefficient of $R=0.977$ ( $p=0.004$ ), and the intercept and slope of the line 


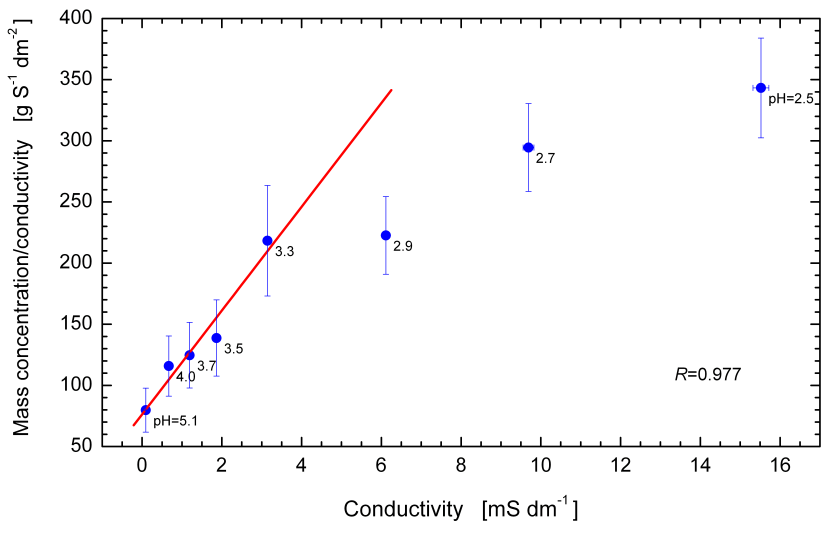

Fig. 1. The relationship for deriving the average molecular mass and acid dissociation constant of HULIS assuming one dissociable carboxyl functional group per molecule. The correlation coefficient $(R)$ and the solution $\mathrm{pH}$ values are also indicated.

are $A=(76 \pm 9) \mathrm{g} \mathrm{S}^{-1} \mathrm{dm}^{-2}$ and $B=(42 \pm 5) \times 10^{3} \mathrm{~g} \mathrm{~S}^{-2} \mathrm{dm}^{-1}$, respectively. The data for the three most concentrated solutions deviate substantially from the linear line. These were saturated solutions, and the presence of some insoluble HULIS could be visually observed on the walls of the glass vial. The activity of these three samples can not be approximated by their concentrations. Moreover, formation of HULIS aggregates can not be excluded in the upper end of the concentration interval investigated (Tabazadeh, 2005; Salma et al., 2008) which can lead to latent concentrations. The intercept $\left(A=M / \Lambda_{0}\right)$ of the linear line was further utilized to derive the average molecular mass of HULIS. The limiting molar conductivity of HULIS was represented by the molar ionic conductivity of the hydrogen cation to be of $\lambda_{\mathrm{H}^{+}}=325 \mathrm{~S} \mathrm{~cm}^{2} \mathrm{~mol}^{-1}$ at a temperature of $20^{\circ} \mathrm{C}$ (LandoltBörnstein, 1960). In this approach, it is assumed implicitly that the molar ionic conductivity of the anion formed by the dissociation (HULIS ${ }^{-}$) is negligible to the conductivity of $\mathrm{H}^{+}$cation. This is a reasonable assumption due to the very diverse masses (and mobilities) for the hydrogen and HULIS ions. In the other extreme case, the molar ionic conductivity of the HULIS anion was approximated by the molar ionic conductivity of common small anions of approximately $\lambda_{\text {HULIS }^{-}} \approx 74 \mathrm{~S} \mathrm{~cm}^{2} \mathrm{~mol}^{-1}$, which yielded in a limiting molar conductivity of $\lambda_{\mathrm{H}^{+}}+\lambda_{\mathrm{HULIS}^{-}} \approx 400 \mathrm{~S} \mathrm{~cm}^{2} \mathrm{~mol}^{-1}$. The average molecular masses corresponding to the negligible and significant molar anionic conductivities were 250 and $310 \mathrm{Da}$, respectively. The interval of the average molecular mass set by these results is in excellent agreement with the data reported earlier and summarized in Sect. 3.1. It is worth emphasizing that the range presented here was obtained by an electrochemical approach which differs in principles and realization from the previously utilized, mainly instrumental analytical and optical methods.

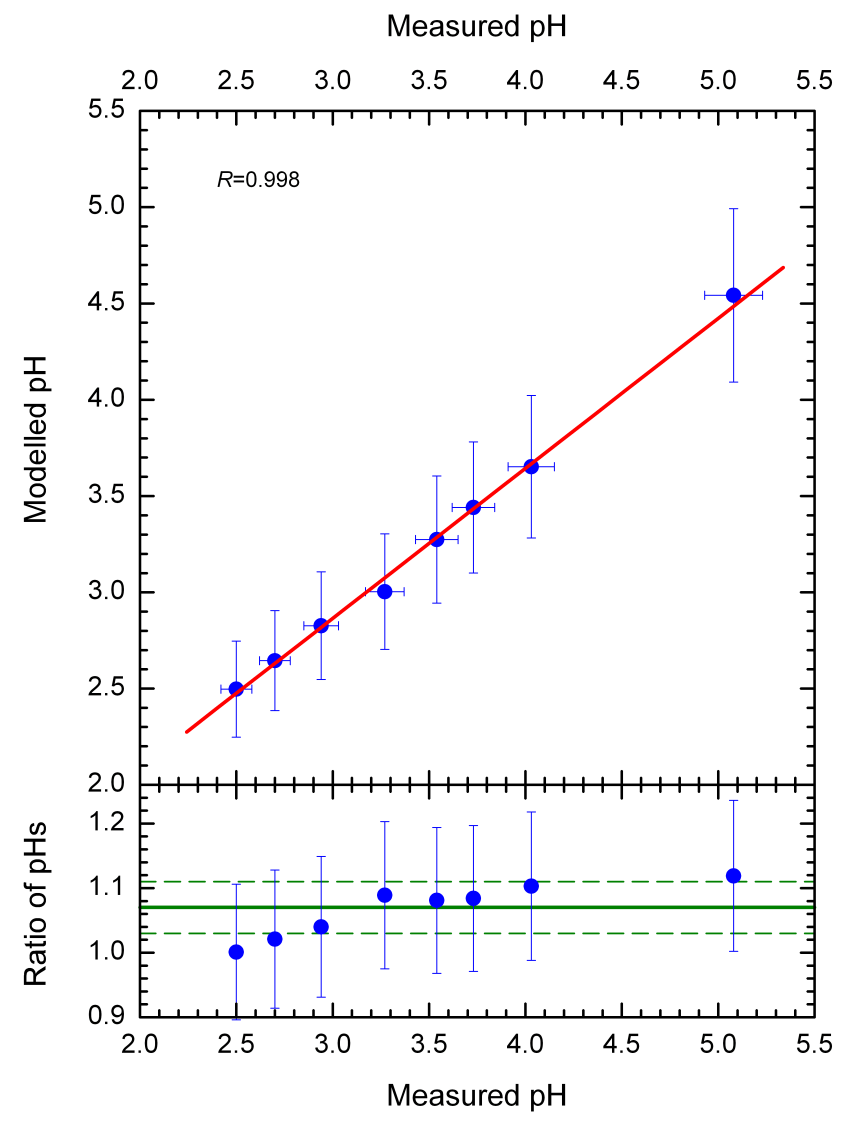

Fig. 2. Scatter plot of the modelled and measured solution $\mathrm{pH}$ values, and their individual ratios. The correlation coefficient $(R)$ and the mean measured-to-modelled $\mathrm{pH}$ ratio and its standard deviation of $1.07 \pm 0.04$ are also indicated by solid and dashed lines, respectively.

\subsection{Acid dissociation constant and solution $\mathrm{pH}$}

The intercept and slope of the fitted linear line for Eq. (1) was further used to calculate the acid dissociation constant of the carboxyl group as $\mathrm{p} K=-\log \left[A^{2} /(B M)\right]$ for the molecular mass interval derived in Sect. 3.2. It was assumed that an average molecule of HULIS contains one dissociable carboxyl group. The $\mathrm{p} K$ values derived for the negligible and significant anionic conductivities were 3.3 and 3.4, respectively. These acidity constants correspond to moderately strong/weak common organic acids as formic acid ( $\mathrm{p} K=3.74$ ) or mandalic acid ( $\mathrm{p} K=3.41$; Lide, 2004). The values obtained are in excellent agreement with that for fulvic and humic acids of $\mathrm{p} K=3.4$ and 3.7, respectively (Porasso et al., 2002), and with that for the SRFA standard of 3.8 (International Humics Substances Society) and of 3.6 (Gustafsson, 2001). The acidity constant is well comparable to the major maximum at $\mathrm{p} K=4.0$ estimated by Samburova et al. (2007) for pure $\mathrm{PM}_{1}$ atmospheric HULIS samples. 
Finally, solution $\mathrm{pH}$ was calculated for data validation purposes by utilizing the dissociation degree of HULIS expressed from Eq. (1) as

$\left[\mathrm{H}^{+}\right]=\alpha c=\frac{1}{2}\left(-K+\sqrt{K^{2}+4 K c}\right)$,

where $\left[\mathrm{H}^{+}\right]$stands for the concentration of hydrogen cation. The possible deviation of the activity coefficients from the unity was neglected. The modelled values were compared to the measured $\mathrm{pH}$ data. For the molecular masses of 250 and $310 \mathrm{Da}$, the correlation between the modelled and measured $\mathrm{pH}$ data was very strong with a coefficient of $R=0.998$ $(p<0.0001)$. Nevertheless, the mean ratios of the measured to modelled $\mathrm{pH}$ data for both molecular masses were $1.07 \pm 0.04$, which differs slightly but significantly from the unity. Scatter plot of the modelled and measured $\mathrm{pH}$ values and their individual ratios for an average molecular mass of $250 \mathrm{Da}$ are displayed in Fig. 2 as example. It is seen that the difference mainly occurs in the most diluted five samples, and that the data for the most concentrated three solutions are somewhat separated again from the others. It means that there was somewhat more hydrogen cation present in the diluted solutions than it was calculated by the model in which a discrete number of dissociable carboxyl group of one was considered. Dissociation of the hydroxyl groups present in HULIS molecules is thought to be negligible because of the acidic $\mathrm{pH}$ interval.

A simple but reasonable method of estimating the average number of dissociable carboxyl groups is to divide the limiting molar conductivity $\left(\Lambda_{0}\right)$ of HULIS experimentally determined by Kohlrausch's empirical equation (see Salma et al., 2008) for molecular masses of 250 and $310 \mathrm{Da}$ by the molar ionic conductivity $\left(\lambda_{\mathrm{H}^{+}}+\lambda_{\text {HULIS }^{-}}\right)$of HULIS. For the significant and negligible anionic conductivities of HULIS, the mean number of dissociable carboxyl group contained in an average HULIS molecule was expressed by an interval between 1.1 and 1.4. The contribution of some other watersoluble organic compounds (like certain organo-sulphates) possibly present in the HULIS sample to the measured conductivity was regarded to be of little consequence because the dissociation of the potential sulphate esters also yields one hydrogen cation similarly to the carboxyl group. It indicates implicitly that the relevant organo-sulphates likely contain approximately one sulphate ester (bond) in their molecule.

\section{Conclusions}

In a previous paper (Salma et al., 2008), concentration dependence of the van't Hoff factor for HULIS (which represents the average number of ions into which a molecule actually dissociates when dissolved) was experimentally determined. The relationship was presented in form of three parametric curves for the stoichiometric dissociation number (the maximum number of ions the molecule dissociates to when dissolved) of $v=2,3$ or 4 (see Fig. 5 of Salma et al., 2008). The conclusions of the present paper refine the possibilities described in that paper practically to one function belonging to the parameter $\nu=2$.

The carboxyl functional group in HULIS exhibits moderately strong/weak acid character. Its dissociation depends on the interactions with other relevant chemical species as water soluble organic constituents and ions internally mixed in the droplets of real atmospheric aerosol. Nevertheless, the dissociation may be influenced in a lesser extent than generally expected because HULIS were found to be stronger acid than previously indicated and anticipated. The results are also in line with our general knowledge and ideas on the presence of organo-sulphates in the water-soluble organic aerosol. Although pure HULIS are already considered as an extremely complex mixture of interacting substances, studies incorporating their external interactions are also desirable as the next step of research because these relationships can modify or even determine the role that HULIS play in the real atmosphere.

Acknowledgements. The financial support of the Hungarian Scientific Research Fund (contracts K61193 and K67994) is appreciated. The authors thank R. Ocskay for her help in the sample preparation.

Edited by: V. F. McNeill

\section{References}

Decesari, S., Facchini, M. C., Fuzzi, S., and Tagliavini, E.: Characterization of water soluble organic compounds in atmospheric aerosol: a new approach, J. Geophys. Res., 105, 1481-1489, 2000.

Decesari, S., Fuzzi, S., Facchini, M. C., Mircea, M., Emblico, L., Cavalli, F., Maenhaut, W., Chi, X., Schkolnik, G., Falkovich, A., Rudich, Y., Claeys, M., Pashynska, V., Vas, G., Kourtchev, I., Vermeylen, R., Hoffer, A., Andreae, M. O., Tagliavini, E., Moretti, F., and Artaxo, P.: Characterization of the organic composition of aerosols from Rondônia, Brazil, during the LBASMOCC 2002 experiment and its representation through model compounds, Atmos. Chem. Phys., 6, 375-402, 2006, http://www.atmos-chem-phys.net/6/375/2006/.

Dinar, E., Taraniuk, I., Graber, E. R., Katsman, S., Moise, T., Anttila, T., Mentel, T. F., and Rudich, Y.: Cloud Condensation Nuclei properties of model and atmospheric HULIS, Atmos. Chem. Phys., 6, 2465-2482, 2006, http://www.atmos-chem-phys.net/6/2465/2006/.

Fuzzi, S., Decesari, S., Facchini, M. C., Matta, E., Mircea, M., and Tagliavini, E.: A simplified model of the water soluble organic component of atmospheric aerosols, Geophys. Res. Lett. 28, 4079-4082, 2001.

Fuzzi, S., Andreae, M. O., Huebert, B. J., Kulmala, M., Bond, T. C., Boy, M., Doherty, S. J., Guenther, A., Kanakidou, M., Kawamura, K., Kerminen, V.-M., Lohmann, U., Russell, L. M., and Pöschl, U.: Critical assessment of the current state of scientific knowledge, terminology, and research needs concerning the role of organic aerosols in the atmosphere, climate, and global change, Atmos. Chem. Phys., 6, 2017-2038, 2006, http://www.atmos-chem-phys.net/6/2017/2006/. 
Graber, E. R. and Rudich, Y.: Atmospheric HULIS: How humiclike are they? A comprehensive and critical review, Atmos. Chem. Phys., 6, 729-753, 2006, http://www.atmos-chem-phys.net/6/729/2006/.

Gustafsson, J. P.: Modeling the acid-base properties and metal complexation of humic substances with the Stockholm humic model, J. Colloid Interf. Sci., 244, 102-112, 2001.

Kiss, G., Tombácz, E., Varga, B., Alsberg, T., and Persson, L.: Estimation of the average molecular weight of humic-like substances isolated from fine atmospheric aerosol, Atmos. Environ., 37, 3783-3794, 2003.

Landolt-Börnstein Zahlenwerte und Funktionen. Eigenschaften der Materie in ihren Aggregatzustaenden, 7. Teil, Elektrische Eigenschaften II., Springer, Berlin, p. 262 and 271, 1960.

Lide, D. L. (Ed.): Handbook of chemistry and physics, CRC Press, 85th edition, Boca Raton, 2004.

McFiggans, G., Artaxo, P., Baltensperger, U., Coe, H., Facchini, M. C., Feingold, G., Fuzzi, S., Gysel, M., Laaksonen, A., Lohmann, U., Mentel, T. F., Murphy, D. M., O’Dowd, C. D., Snider, J. R., and Weingartner, E.: The effect of physical and chemical aerosol properties on warm cloud droplet activation, Atmos. Chem. Phys., 6, 2593-2649, 2006, http://www.atmos-chem-phys.net/6/2593/2006/.

Porasso, R. D., Benegas, J. C., Van den Hoop, M. A. G. T., and Paoletti, S.: Analysis of trace metal humic acid interactions using counterion condensation theory, Environ. Sci. Technol., 36, 3815-3821, 2002.

Salma, I., Ocskay, R., Chi, X., and Maenhaut, W.: Sampling artefacts, concentrations and chemical composition of fine watersoluble organic carbon and humic-like substances in a continental urban atmospheric environment, Atmos. Environ., 41, 41064118, 2007.
Salma, I., Ocskay, R., and Láng, G. G.: Properties of atmospheric humic-like substances - water system, Atmos. Chem. Phys., 8, 2243-2254, 2008, http://www.atmos-chem-phys.net/8/2243/2008/.

Samburova, V., Zenobi, R., and Kalberer, M.: Characterization of high molecular weight compounds in urban atmospheric particles, Atmos. Chem. Phys., 5, 2163-2170, 2005, http://www.atmos-chem-phys.net/5/2163/2005/.

Samburova, V., Didenko, T., Kunenkov, E., Emmenegger, Ch., Zenobi, R., and Kalberer, M.: Functional group analysis of highmolecular weight compounds in the water-soluble fraction of organic aerosols, Atmos. Environ., 41, 4703-4710, 2007.

Tabazadeh, A.: Organic aggregate formation in aerosols and its impact on the physicochemical properties of atmospheric particles, Atmos. Environ., 39, 5472-5480, 2005.

Tagliavini, E., Moretti, F., Decesari, S., Facchini, M. C., Fuzzi, S., and Maenhaut, W.: Functional group analysis by $\mathrm{H}$ $\mathrm{NMR} /$ chemical derivatization for the characterization of organic aerosol from the SMOCC field campaign, Atmos. Chem. Phys., 6, 1003-1019, 2006, http://www.atmos-chem-phys.net/6/1003/2006/.

Tsigaridis, K. and Kanakidou, M.: Secondary organic aerosol importance in the future atmosphere, Atmos. Environ., 41, 46824692, 2007.

Varga, B., Kiss, G., Ganszky, I., Gelencsér, A., and Krivácsy, Z.: Isolation of water soluble organic matter from atmospheric aerosol, Talanta, 55, 561-572, 2001. 